\title{
CLINICAL PROFILE AND COMPARISON OF OUTCOME OF TREATMENT BY EXTRACORPOREAL SHOCK WAVE LITHOTRIPSY AND URETERORENOSCOPY IN THE MANAGEMENT OF UPPER URETERIC CALCULI
}

\author{
SHARANJIT SINGH BASRA ${ }^{1 *}$, HIREMATH RN ${ }^{2}$, VISHAL VERMA ${ }^{3}$, DOBI SRAVAN KUMAR ${ }^{4}$ \\ ${ }^{1}$ Surgical specialist, Amritsar, Punjab, India. ${ }^{2}$ Public Health Specialist, Bengaluru, Karnataka, India. ${ }^{3}$ Surgical specialist, New Delhi, India. \\ ${ }^{4}$ Medical officer, New Delhi, India. Email: sharanbasra77@gmail.com
}

Received: 19 April 2021, Revised and Accepted: 06 May 2021

\section{ABSTRACT}

Objective: Urinary calculi are the third most common affliction of the urinary tract, exceeded only by urinary tract infections and pathologic conditions of the prostate. This study was carried out to assess the safety, efficacy, and compare structural and functional outcome after treating the patients of the upper ureteric calculus with Extracorporeal Shock Wave Lithotripsy (ESWL) and Ureterorenoscopy (URS).

Methods: A prospective study was conducted on patients with the upper ureteric stone of size $0.5-1.5 \mathrm{~cm}$. A total of 50 patients were included in the study by means of systematic random sampling so as to get 25 patients in each category of ESWL and URS for the treatment of their upper ureteric calculi.

Results: The age ranged from 15 years to 55 years. There were 36 males and 14 females in the study of 50 patients, 43 (86\%) presented with pain, followed by $4(8 \%)$ presented with hematuria. Twenty-eight (56\%) of the patients had stone in the range of $0.5-1.0 \mathrm{~cm}$, and 22 (44\%) of the patients had stone in the range of 1.0-1.5 cm. Sixteen (32\%) patients had stone within $2 \mathrm{~cm}$ of the pelvi-ureteric junction, and $13(26 \%)$ had stone within $2 \mathrm{~cm}$ of the sacroiliac joint. Twenty-one ( $42 \%$ ) patients had stone in between these two. Of the 50, 25 patients (50\%) underwent shock wave lithotripsy, 25 patients (50\%) underwent URS. In the ESWL group, 21 (84\%) patients were stone-free after single sitting of ESWL. Four patients (16\%) who required Re ESWL, after repeat ESWL two became stone-free however 2 (8\%) patient of 1.0-1.5 cm category required secondary procedure, that is, URS and became stone free. To achieve stone-free 1.24 procedure was required per patients. Of the 25 patients in the ESWL group, 2 (8\%) patient (one steinstrass case and one poor fragmentation case) required secondary procedure. They underwent URS. Both the patient belonged to $1.0-1.5 \mathrm{~cm}$ group. URS was done using semirigid ureteroscope using pneumatic Lithoclast. In our study, two patients of each $0.5-1.0 \mathrm{~cm}$ and $1.0-1.5 \mathrm{~cm}$ category did not become stone free. These four patients were subjected to ESWL and became stone free.

Conclusion: The management of the ureteral stone should be decided on individual basis, based on stone size, location, symptoms, obstruction, and the availability of the instruments. For stones of 0.5-1.0 cm, ESWL is the treatment of choice for the upper ureteric stones, with very low ReESWL (1.12 sittings) without any requirement of ancilliary procedure. URS may be used for the upper ureteric stones but requirement of ancilliary procedure is high $11.11 \%$. For stones between $1.1 \mathrm{~cm}$ and $1.5 \mathrm{~cm}$, ESWL is the preferred modality of treatment for the upper ureteric stones.

Keywords: Extracorporeal, Shock wave lithotripsy, Ureterorenoscopy. Ureteric calculi.

(c) 2021 The Authors. Published by Innovare Academic Sciences Pvt Ltd. This is an open access article under the CC BY license (http://creativecommons.org/ licenses/by/4.0/) DOI: http://dx.doi.org/10.22159/ajpcr.2021v14i6.41844. Journal homepage: https://innovareacademics.in/journals/index.php/ajpcr

\section{BACKGROUND}

Urinary calculi are the third most common affliction of the urinary tract, exceeded only by urinary tract infections and pathologic conditions of the prostate [1]. Urinary stones have plagued humans since the earliest records of civilization. Stone disease not only affects the patients but also the national economy. The diverse manifestation of urolithiasis provides a very interesting epidemiological study from the standpoint of geography, socio-economic status, nutrition, and culture [2]. There has been a continuous search for the cost effectiveness of different treatment modalities for urolithiasis not only to treat but also to prevent its recurrence.

Ureteral calculi are stones that usually form in the renal collecting system, then progress down the ureter. They tend to become lodged at sites where the ureter narrows. The three most common entrapment sites are at the ureteropelvic junction, over the iliac vessels and at the ureteral meatus [3].

The management of ureteral calculi is constantly evolving, and advances in technology, new medications and the application of pharmacotherapy continue to alter our approach to ureterolithiasis. In the 10 years, between the 1997 guidelines for ureteral calculus management [3] and the 2007 European Association of Urology-American Urological
Association (EAU-AUA) consensus guidelines [4], several treatment options were introduced, refuted, or altered. Clinicians today can choose from extracorporeal shock wave lithotripsy (ESWL), percutaneous antegrade nephrostomy ureterolithotomy, retrograde ureterorenoscopy (URS) with or without intracorporeal lithotripsy, laparoscopic ureterolithotomy, and occasionally open ureterolithotomy. It has been suggested that with the newer less invasive forms of therapy a conservative approach is undertaken less often.

\section{ESWL or URS for upper ureteric calculi?}

Several studies have demonstrated the clinical efficacy of ESWL in fragmenting and clearing ureteric calculi [5-9]. Supporters of ESWL claim that it is effective and non-invasive and can be done on an outpatient basis with intravenous sedation [10]. Advances in ureteroscope technology with the introduction of small caliber semirigid and flexible URS combined with the introduction of Holmium YAG laser have improved stone-free rates following URS while decreasing the risk of complications [11-14]. Both the treatment modalities have pros and cons as evidenced by various studies.

In view of above background, we carried out a study to assess the safety, efficacy, and compare structural and functional outcome after treating the patients of the upper ureteric calculus with ESWL and URS. 


\section{METHODS}

This prospective study was conducted at one of the Super Specialty Hospital, in Northern India. Patients with the upper ureteric stone of size $0.5-1.5 \mathrm{~cm}$ were included in the study. Pediatric population of $<5$ years of age, adults with impacted stone or ureter distal to stone not visualized on intravenous urography, presence of infection, patients with bleeding diathesis and gross obesity, and pregnancy were excluded from the study. A total of 50 patients were included in the study by means of systematic random sampling so as to get 25 patients in each category of ESWL and URS for the treatment of their upper ureteric calculi and their complete biodata, symptomatology, and clinical findings were recorded in detail as per the pretested Performa and relevant investigations were carried out. Data were entered into Excel Sheet and analyzed by means of Epi-info version 6.0.

\section{RESULTS}

The age ranged from 15 years to 55 years. Of the 50 patients, 29 patients were in the age group of 15-35 years, 16 were in the age group of $35-45$ years, and 5 were in the age group of $45-55$ years. There were 36 males and 14 females in the study. The male to female ratio was 1.38M: $1 \mathrm{~F}$. Of 50 patients, $43(86 \%)$ presented with pain followed by $4(8 \%)$ presented with hematuria. Dysuria was the least common presentation in patients with the upper ureteric stone accounting only for $4 \%$, that is, two patients. Of the 50 patients, $32(64 \%)$ patients had stone on the right side, 15 (30\%) had stone on left and three $(6 \%)$ patients had bilateral stone. A total of 50 patients were subjected to ESWL and URS alternately. Twenty-eight (56\%) of the patients had stone in the range of $0.5-1.0 \mathrm{~cm}$, and $22(44 \%)$ of the patients had stone in the range of $1.0-1.5 \mathrm{~cm}$. The smallest stone was of $0.7 \mathrm{~cm}$ and the largest was of $1.5 \mathrm{~cm}$. Sixteen (32\%) patients had stone within $2 \mathrm{~cm}$ of the pelvi-ureteric junction (PUJ), and $13(26 \%)$ had stone within $2 \mathrm{~cm}$ of the sacroiliac joint. Twenty-one (42\%) patients had stone in between these two. Of the 50, 25 patients (50\%) underwent shock wave lithotripsy, and 25 patients (50\%) underwent URS (Table 1 and Figs. 1-3).

\section{Stone-free rate}

The stone-free rate provides an objective outcome measure for evaluating the efficacy of treatment. Stone-free status is especially important for patients with ureteral stones because residual fragments are much less likely to remain "clinically dormant" in the ureter than are most fragments (other than struvite) remaining in the kidney. A plain abdominal radiograph (KUB) was used to assess stone-free status.

\section{ESWL}

A total of 25 patients were subjected ESWL. Sixteen (64\%) of the patients had stone in the range of $0.5-1.0 \mathrm{~cm}$. Nine $(18 \%)$ patients had stone in the range of $1.1-1.5 \mathrm{~cm}$. The smallest stone was of $0.7 \mathrm{~cm}$ and the largest was of $1.4 \mathrm{~cm}$. The mean size of the stone was $1.06 \mathrm{~cm}$. Four (16\%) patients had stone within $2 \mathrm{~cm}$ of the PUJ, 5 (20\%) had stone within $2 \mathrm{~cm}$ of the sacroiliac joint. Sixteen patients had stone in between these two in the patient who underwent ESWL. Of the total 25 patients who underwent ESWL, two (8\%) patients were stented preoperatively. Rest $23(92 \%)$ the lithotripsy was done on unstented. Both the stone were in the range of 1.0-1.5 cm. The average shock wave given was 3000-4000. Of the 25 patients in ESWL group, 21 patients (84\%) received 3000 shock wave, four patients (16\%) received shock wave 3000-4000. Of the 25 in the ESWL group, 21 (84\%) patients were stone free after the treatment of ESWL. Of the 16 patients with stone size in between 0.5 and $1.0 \mathrm{~cm}, 14$ patients (87.5\%) were stone free after ESWL whereas of the nine patients with stone size $1.0-1.5 \mathrm{~cm}, 7$ (77.7\%) were stone free after ESWL. Twenty-one (84\%) patients were stone free after single procedure of ESWL. Second procedure was required in four (16\%) patients ( 3 ESWL and one secondary procedure, i.e. URS) of the total 25 patients. Four patients (16\%) who required Re ESWL, two of them required once and became stone free. Two patients required twice, but one developed steinstrass and second had poor fragmentation, and both required URS for complete clearance. To achieve stone free 1.12 procedure was required per patients in $0.5-1.0 \mathrm{~cm}$ group and 1.57 sittings of ESWL and two secondary procedures were required for 1.0$1.5 \mathrm{~cm}$ group to make them stone free. Of the 25 patients in the ESWL group, 23 (96\%) patients were stone free after the treatment of ESWL. Two patients required secondary procedure, who underwent URS and became stone free. One patient (4\%) had steinstrass after ESWL and he underwent URS for complete clearance. This patient belonged to 1.0-1.5 cm group (Table 2).

\section{URS}

A total of 25 patients were subjected to URS. Eighteen (72\%) of the patients had stone in the range of $0.5-1.0 \mathrm{~cm}$. Seven $(28 \%)$ patients had stone in the range of $1.1-1.5 \mathrm{~cm}$. Three (12\%) patients had stone within $2 \mathrm{~cm}$ of the PUJ, 12 (48\%) had stone within $2 \mathrm{~cm}$ of the sacroiliac joint. Ten patients had stone in between these two in the patient who underwent URS. All were stented postoperatively in the URS group and none of the stones were impacted 25 patients.

Of the 25 in the URS group, 21 (84\%) patients were stone free after the treatment of URS. Of the 18 patients with stone size in between 0.5 and $1.0 \mathrm{~cm}, 16$ patients (88.8\%) were stone free after URS whereas of the seven patients with stone size $1.0-1.5 \mathrm{~cm}, 5(71.4 \%)$ were stone free after URS. Out of the 25 patients of URS group, two patients of each $0.5-1.0 \mathrm{~cm}$ and $1.0-1.5 \mathrm{~cm}$ category did not become stone free. These four patients were subjected to ESWL and became stone free.

\section{DISCUSSION}

In the present study, 50 consecutive patients with the upper ureteric stones were taken with stone size of $0.5-1.5 \mathrm{~cm}$. These patients were studied, observed, and compared based on the treatment modality as per the predesigned pro forma.

\section{Pre-operative parameters}

Age distribution and sex distribution

In the present study, the age ranged from 15 years to 55 years. Of the 50 patient's maximum, that is, 29 patients (58\%) were in the age group of 15-35 years. The age and the sex distribution is comparable to most of the studies in the literature. Abhijit et al. [15] in their study of 846 patients had age in the range of 9-69 years with male to female ratio of 1.8:1.

\section{Presentation}

In our study, pain was the most common symptoms of presentation seen in $43(86 \%)$ presented followed by $4(8 \%)$ presented with hematuria. Dysuria was the least common presentation in patients with the upper ureteric stone accounting only for $4 \%$, that is, two patients. In a study conducted by Abhijit et al. [15], on 846 patients the most common mode of presentation were colic in 801 patients.

\section{Stone size}

Out of 50 patients, $28(56 \%)$ patients had stone in the range of $0.5-1.0 \mathrm{~cm} .44 \%$, that is, 22 patients had stone in the range of $1.0-$ $1.5 \mathrm{~cm}$. The smallest stone was of $0.7 \mathrm{~cm}$ and the largest was of $1.5 \mathrm{~cm}$.

Segura and associates (1997) reported in the AUA guidelines [16] on the management of patients with ureteral calculi that for stones smaller than $5 \mathrm{~mm}$, the spontaneous passage rate in the distal ureter and proximal ureter ranged from 71 to $98 \%$ and from 29 to $98 \%$, respectively, whereas stones larger than $5 \mathrm{~mm}$ had a lower spontaneous passage rate, ranging from 10 to $53 \%$ and 25 to $53 \%$ for proximal and distal ureteral calculi, respectively.

\section{ESWL}

In the present study, 25 patients were subjected to ESWL. Sixteen $(64 \%)$ of the patients had stone in the range of $0.5-1.0 \mathrm{~cm}, 36 \%$, that is, nine patients had stone in the range of $1.1-1.5 \mathrm{~cm}$. The smallest stone was of $0.7 \mathrm{~cm}$ and the largest was of $1.4 \mathrm{~cm}$. The mean size of the stone was $1.05 \mathrm{~cm}$. 
According to Segura et al., 1997 [16], majority of ureteral stones pass spontaneously, especially stones $<5 \mathrm{~mm}$ in diameter, and thus can be treated with expectant management. Stones larger than $8 \mathrm{~mm}$, however, are unlikely to pass spontaneously in a timely fashion without causing significant symptoms and possible renal damage from obstruction. Experience with various treatment modalities has demonstrated differences in efficacy when they are applied to large ureteral stones. In the meta-analysis performed by the AUA, ESWL for the in situ treatment of large $(>1 \mathrm{~cm})$ ureteral stones achieved a stone-free rate of $76 \%$, independent of initial stone location.

The AUA Ureteral Stones Clinical Guidelines Panel performed a metaanalysis of all articles on ureteral calculi published during a 30-year period from 1966 to 1996 (Segura et al., 1997) [16]. The results were analyzed for ESWL in situ, ESWL after "pushback," ESWL after stent insertion, ureteroscopy, and open surgical stone removal. The stonefree rates of ESWL and URS were $84 \%$ and $56 \%$, respectively, for stones smaller than $1 \mathrm{~cm}$ and $72 \%$ and $44 \%$, respectively, for stones larger than $1 \mathrm{~cm}$. The risks of significant complications after ESWL and URS were $4 \%$ and $11 \%$, respectively. Although open stone surgery had a median stone-free rate of $97 \%$, it was associated with longer hospitalization and greater postoperative morbidity and therefore was not recommended as a first-line intervention. As a guideline, because of its greater efficacy and lower morbidity, the panel suggested that ESWL, either in situ or after pushback, should be the primary approach for stones smaller than $1 \mathrm{~cm}$ in the proximal ureter. For stones larger than $1 \mathrm{~cm}$ in diameter, ESWL, PNL, and URS are all acceptable choices. Initial experience with

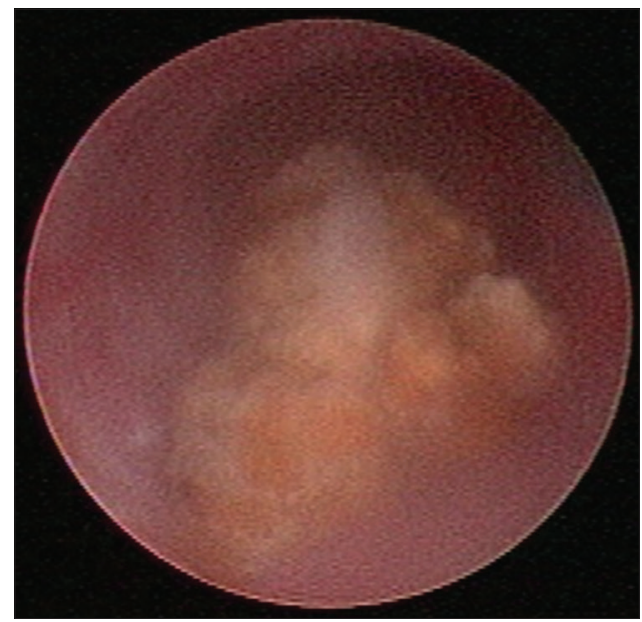

Fig. 1: Stone visualized in ureter

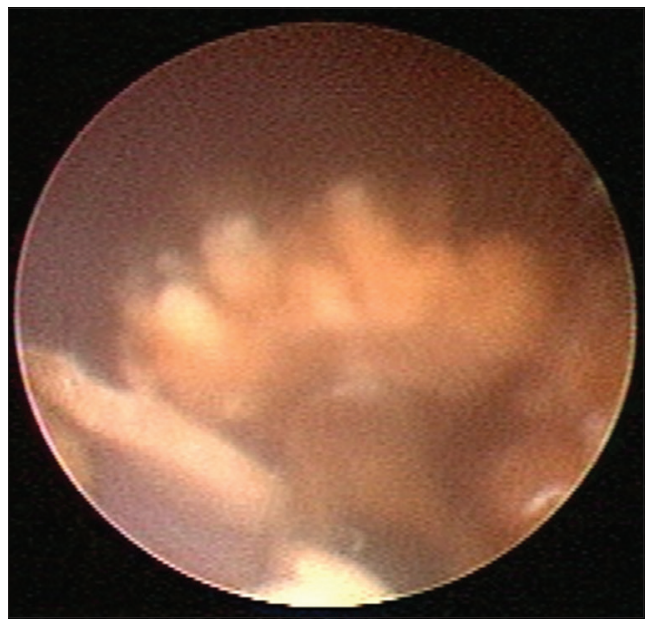

Fig. 2: Fragmented stone using Laryngeal Mask Airway stone breaker by $1 \mathrm{~mm}$ probe through the ureteroscope (up to $<1 \mathrm{~mm}$ size fragment
ESWL suggested that placement of a ureteral stent before treatment facilitated stone fragmentation and passage (Liong et al., 1989) [17]. However, the AUA meta-analysis demonstrated no improvement in stone fragmentation for these patients, so this practice was discouraged. Placement of a ureteral stent may be appropriate for other indications, such as in the management of pain, for the relief of obstruction, and in the treatment of difficult-to-visualize stones. Stent placement is mandatory in patients who have a solitary obstructed kidney.

Ziaee et al. [18] in their study of 197 patients showed that ESWL has enough capacity for the management of proximal ureteral stones 10$15 \mathrm{~mm}$ in size. Although URS tends to make patients stone-free faster, because of the minimally invasive nature of ESWL, patients still favored it over ureteroscopy.

Olsburg et al. [19] suggested that ESWL is as effective as, if not better than, URS in treating ureteric calculi and should be considered, to avoid ureteric injury and other morbidity, as the primary treatment for stones in all positions in the ureter. The reasons stated for poor stone clearance with ESWL in impacted upper ureteral calculi are that they are more resistant to fragmentation because of lack of liquid interface surrounding the stone thus reducing cavitation activity. Besides push back procedure and even DJ stenting can be quite difficult because of the stone adherence to the edematous ureteral wall or due to fibro epithelial polyps obstructing the ureter

Abhijit et al. [15] in their study of 846 patients concluded that though the success rates of URS for the upper ureteric stones approach 90-95\%. However, URS is a more morbid procedure with increased hospitalization and higher complication rate. Even with small-caliber scopes ureteric perforation rates are $0-5 \%$ and stricture rates $1-4 \%$. Conversely ESWL has almost similar success rates of $91 \%$ with low complication rate and failure rate with far better patient acceptance. We in our study have treated 14 patients of stone size $0.5 \mathrm{Cm}-1.0 \mathrm{~cm}$ and seven patients of stone size $1.0-1.5 \mathrm{~cm}$ by ESWL.

In the present study of the 25 patients in the ESWL group, 21 (84\%) patients were stone free after single sitting of ESWL. Four patients (16\%) who required Re ESWL, after repeat ESWL two became stone

Table 1: Basic and pre-operative clinical profile of study participants

\begin{tabular}{ll}
\hline & No of patients (n=50) (\%) \\
\hline Age range & \\
$15-35$ & $29(58)$ \\
$35-45$ & $16(32)$ \\
$45-55$ & $05(10)$ \\
Sex & \\
Male & $30(60)$ \\
Female & $20(40)$ \\
Symptoms & \\
Pain & $43(86)$ \\
Hematuria & $4(8)$ \\
Fever & $1(2)$ \\
Dysuria & $2(4)$ \\
Stone side & \\
Right & $32(64)$ \\
Left & $18(36)$ \\
Stone size in cm & \\
$0.5-1.0$ & $28(56)$ \\
$1.0-1.5$ & $22(44)$ \\
Stone location & \\
Within 2 cm of PUJ & $16(32)$ \\
Within 2 cm of SI joint & $13(26)$ \\
In between & $21(42)$ \\
Procedure & \\
ESWL & $25(50)$ \\
URS & $25(50)$ \\
\hline ESWL: Extracorporeal shock wave lithotripsy & URS: Ureterorenoscopy \\
& \\
\hline &
\end{tabular}

ESWL: Extracorporeal shock wave lithotripsy, URS: Ureterorenoscopy 


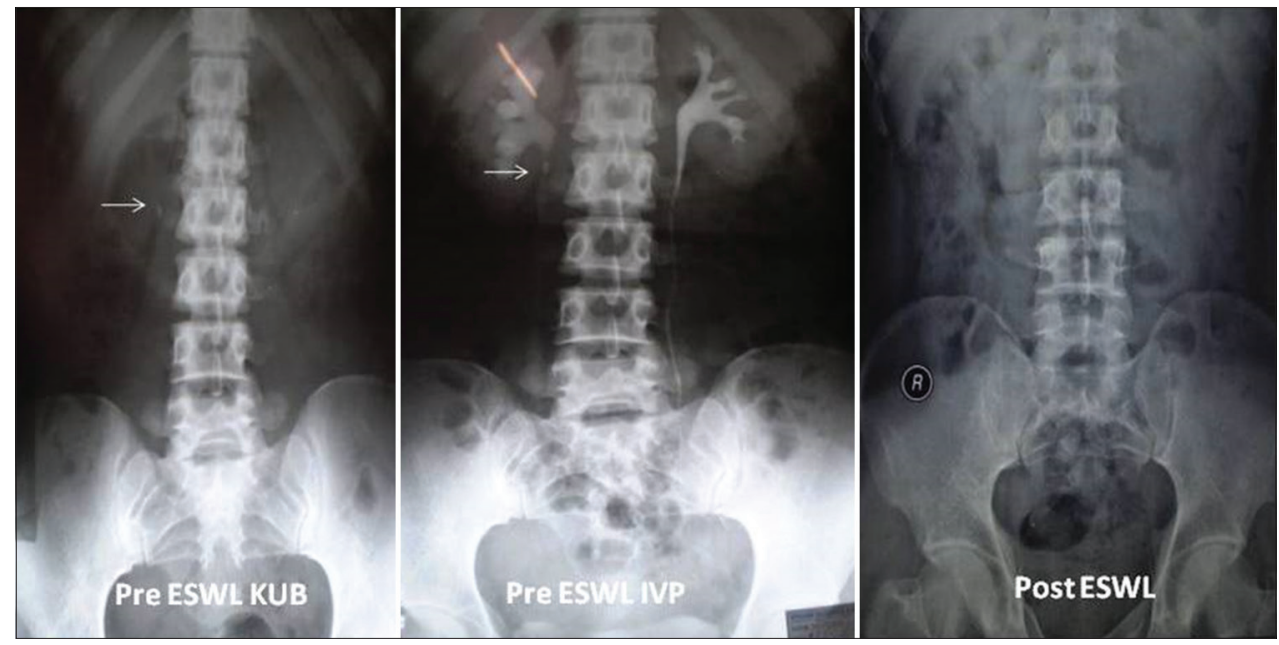

Fig. 3: Pre/post-extracorporeal shock wave lithotripsy X-ray films

Table 2: Comparative analysis between ESWL and URS

\begin{tabular}{|c|c|c|c|c|}
\hline \multicolumn{3}{|c|}{ Variables under ESWL procedure } & \multicolumn{2}{|c|}{ Variables under URS procedure } \\
\hline Stone size in $\mathrm{cm}$ & No of patients $(n=25$ & & Stone size in $\mathrm{cm}$ & No of patients $(n=25)$ \\
\hline $0.5-1.0$ & $16(64 \%)$ & & $0.5-1.0$ & $18(72 \%)$ \\
\hline $1.0-1.5$ & $9(36 \%)$ & & $1.0-1.5$ & $7(28 \%)$ \\
\hline Stone location & & & Stone location & \\
\hline Within $2 \mathrm{~cm}$ of PUJ & $4(16 \%)$ & & Within $2 \mathrm{~cm}$ of PUJ & $3(12 \%)$ \\
\hline Within $2 \mathrm{~cm}$ of SJ joint & $5(25 \%)$ & & Within $2 \mathrm{~cm}$ of $\mathrm{SJ}$ joint & $12(48 \%)$ \\
\hline In between & $16(64 \%)$ & & In between & $10(40 \%)$ \\
\hline Present & $2(8 \%)$ & & & \\
\hline Absent & $23(92 \%)$ & & & \\
\hline Shock wave & No of patients $(n=25$ & & & \\
\hline 3000 & $21(84 \%)$ & & & \\
\hline $3000-4000$ & $4(16 \%)$ & & & \\
\hline Stone size in $\mathrm{cm}$ & Stone free & & Stone size in $\mathrm{cm}$ & Stone free \\
\hline $0.5-1.0$ & $14 / 16(87.5 \%)$ & & $0.5-1.0$ & $16 / 18(88.8 \%)$ \\
\hline $1.0-1.5$ & $7 / 9(77.7 \%)$ & & $1.0-1.5$ & $5 / 7(71.4 \%)$ \\
\hline Once & $14(87.5 \%)$ & $7(77.7 \%)$ & & \\
\hline Twice & $2(0.12 \%)$ & $2(0.22 \%)$ & & \\
\hline Secondary procedure & Two were subjected & terorenoscopy & Secondary procedure & Four were subjected to ESWL \\
\hline Complication & One patient ( $4 \%$ ) hac & nstrass & Complication & None \\
\hline
\end{tabular}

Table 3: Comparison of Stone-free rate and re ESWL rate after ESWL in different studies

\begin{tabular}{|c|c|c|}
\hline Various studies & $\begin{array}{l}<10 \mathrm{~mm} \\
\text { stone-free rate }\end{array}$ & $\begin{array}{l}>10 \mathrm{~mm} \text { stone- } \\
\text { free rate }\end{array}$ \\
\hline AUA Guidelines 2007 & 90 & 68 \\
\hline Youssef et al. & 83.7 & 83.7 (up to $20 \mathrm{~mm}$ ) \\
\hline Ghoneim et al. & 88.3 & 88.3 (up to $20 \mathrm{~mm}$ ) \\
\hline Riehle and Naslund & 85 & - \\
\hline Graff et al. & $70.1-83$ & - \\
\hline Ziaee et al. & 78.6 & 78.6 (up to $15 \mathrm{~mm}$ ) \\
\hline Abhijit et al. & 95.9 & 85.2 \\
\hline Rassweiler et al. & 85 & - \\
\hline Danuser et al. & 96 & - \\
\hline Mobley et al. & 85.8 & - \\
\hline Present study & 87.5 & 77.7 \\
\hline Various studies & $\begin{array}{l}\text { Retreatment } \\
\text { rate }(<10 \mathrm{~mm})\end{array}$ & $\begin{array}{l}\text { Retreatment rate } \\
(>10 \mathrm{~mm})\end{array}$ \\
\hline AUA Guidelines & 1.19 & 1.38 \\
\hline Lu et al. & 1.15 & 1.6 \\
\hline Youssef et al. & 1.35 & 1.65 \\
\hline Kenneth et al. & 1.4 & 1.7 \\
\hline Present study & 1.12 & 1.57 \\
\hline
\end{tabular}

free however $2(8 \%)$ patient of $1.0-1.5 \mathrm{~cm}$ category required secondary procedure, that is, URS and became stone free. To achieve stone-free 1.24 procedure was required per patients.

According to the AUA guidelines published in 2007, which compiled the data of 24 groups which included 4567 patients and showed that the 1.28 procedures were required to clear the stone per patients. Lu et al. [20] in a study conducted on 115 children concluded that, stone-free rate at 3 months was $94.8 \%$, the re-treatment rate $15.7 \%$, and overall efficacy quotient (EQ) was $83 \%$ after ESWL in children. Six children (5.2\%) failed ESWL. Abhijit et al. [15] in a study on 846 patients, $1.3 \mathrm{~s}$ procedure was required to achieve a success rate of $91.73 \%$ for treating upper ureteric stone over a period of 10 years. Thus, our rate of second procedure is comparable to most of the studies (Table 3).

Of the 25 patients in the ESWL group, two (8\%) patient (one steinstrass case and one poor fragmentation case) required secondary procedure. They underwent URS. Both the patient belonged to $1.0-1.5 \mathrm{~cm}$ group. In a meta-analysis of article published over 30 years, AUA guidelines 2007 concluded a steinstrass rate of $5 \%$ for proximal upper ureteric stone. The results in our study are also comparatively similar. Ahmet et al. [21] in a study of 408 patients had steinstrasse rate of $9.6 \%$ whereas 
Table 4: Comparison of steinstrasse rate and secondary procedure rate after ESWL in different studies

\begin{tabular}{lll}
\hline Various studies & Steinstrasse rate & $\begin{array}{l}\text { Secondary procedure } \\
\text { rate after ESWL }\end{array}$ \\
\hline AUA Guidelines 2007 & 5 & $12 \%$ \\
Youssef et al. & 4.7 & $16.30 \%$ \\
Oblsburg et al. & 5 & - \\
Lu et al. & 5.2 & - \\
Laundau et al. & 3.2 & $3.20 \%$ \\
Ahmet et al. & 9.6 & - \\
Abhijit et al. & - & $8.27 \%$ \\
Present study & 4 & $8.0 \%$ \\
\hline
\end{tabular}

Abhijit et al. [15] in a study of 846 patients had steinstrasse rate of $2 \%$ (Table 4).

According to the guidelines published by AUA in 2007, which compiled data of eight groups which included 416 patients a secondary procedure were required in $12 \%$ of the patients. Yousef et al. [22] in a study conducted on 427 patients concluded the need for auxiliary procedures to be $16.3 \%$ Laundau et al. [23] in a study on 31 patients needed URS and stone removal in one patients who failed after two cycles of ESWL. Abhijit et al. [15] in a study on 846 patients 70 patients $(8.27 \%)$ required secondary procedure to clear there stones. In these, $59 / 70$ underwent ureteroscopy, 8/70 percutaneous nephrolithotomy, and $3 / 70$ open ureterolithotomy for clearance.

\section{URS}

URS was done using semirigid ureteroscope using pneumatic Lithoclast. In our study, two patients of each $0.5-1.0 \mathrm{~cm}$ and $1.0-1.5 \mathrm{~cm}$ category did not become stone free. These four patients were subjected to ESWL and became stone free.

Semirigid ureteroscopes are typically used for treatment of ureteral pathology below the iliac vessels but may be utilized above the iliac vessels especially in female patients (Campbell Walsh, Text Book of Urology, Ninth Edition) [24]. Caution must be used as the semirigid instrument can accommodate some bend but may sustain damage or even fracture when the metal fatigues. This is particularly hazardous in patients with large psoas muscles and longer urethras (i.e. males), in whom it is often difficult to use the semirigid ureteroscope above the iliac vessels (Campbell Walsh, Text Book of Urology, Ninth Edition) [24]. The use of small-caliber ureteroscopes and the advent of balloon dilation or ureteral access sheaths have increased stone-free rates dramatically. Even relatively large-caliber endoscopes without balloon dilation are effective in the lower ureteral stone retrieval. Stone-free rates range from $66 \%$ to $100 \%$ and are dependent on stone burden and location, length of time the stone has been impacted, and the experience of the operator. Complication rates range from $5 \%$ to $30 \%$; the rates increase when manipulations venture into the proximal ureter. Ureteral stricture rates are $<5 \%$. A variety of lithotrites can be placed through an ureteroscope, including electrohydraulic, solid and hollow-core ultrasonic probes, a variety of laser systems, and pneumatic systems such as the Swiss Lithoclast.

Yencilek et al. [25], who treated 1503 patients of ureteral stone with semirigid ureteroscope concluded that Semirigid URS can be the treatment of choice in the lower and midureteral stones. However, it is an invasive and less successful treatment modality for proximal ureteral stones with relatively high complication rates. Fuganti et al. [26] in a study of 1235 patients of ureteral stone treated with semirigid ureteroscope concluded that semirigid URS is a safe procedure with few complications. Larger stones, proximally located (iliac vessels or above) with the previous in situ ESWL in men, are preoperative predictors for intraoperative complications.

Since the publication of the AUA guidelines, significant improvements have been made in ureteroscopic technology. In 2001, the EAU published
"Guidelines on Urolithiasis," in which they performed an analysis of the relevant literature for the 3 years after the AUA publication (Tiselius et al., 2001) [27,28]. They detected a significant improvement in stonefree rates; semirigid and flexible ureteroscopes provided a $90 \%-100 \%$ stone-free rate for distal ureteral calculi and a $74 \%$ stone-free rate for proximal ureteral calculi. In addition, $95 \%$ of patients could be successfully treated with only one endoscopic procedure, and the best results were reported with holmium: YAG laser lithotripsy in the proximal ureter.

\section{CONCLUSION}

The management of the ureteral stone should be decided on individual basis, based on stone size, location, symptoms, obstruction, and the availability of the instruments. Stone-free rate is defined when there is no residual fragment visible on X-ray KUB after 1 month of therapy. For stones of $0.5-1.0 \mathrm{~cm}$, ESWL is the treatment of choice for the upper ureteric stones, with very low Re-ESWL (1.12 sittings) without any requirement of ancillary procedure. URS may be used for the upper ureteric stones but requirement of ancillary procedure is high $11.11 \%$. For stones between $1.1 \mathrm{~cm}$ and $1.5 \mathrm{~cm}$, ESWL is the preferred modality of treatment for the upper ureteric stones. The Re-ESWL (1.57 sittings) and ancillary procedure (22.22\%) though high but is acceptable. Due to larger stone burden, the steinstrasse rate $(4 \%)$ in this group of patients is higher. URS may be used for upper ureteric stones but requirement of ancillary procedure is quite high $28.57 \%$.

\section{REFERENCES}

1. Stoller ML. Urinary stone disease. In: Tanagho EA, McAninch JW, editors. Smith's General Urology. $17^{\text {th }}$ ed. United States: McGraw Hill Lange; 2008. p. 246.

2. Ansari MS, Gupta KP. Impact of socio-economic status in etiology and management of urinary stone disease. Urol Int 2003;70:255-61.

3. American Urological Association. Report on the Management of Ureteral Calculi; 1997. Available from: https://www.auanet.org/a/6327. [Last accessed on 2021 Apr 01].

4. American Urological Association Education and Research, Inc and European Association of Urology. Guideline for the Management of Ureteral Calculi; 2007. Available from: https://www.auanet.org. [Last accessed on 2021 Apr 01]

5. Cummings JM, Boullier JA, Izenberg SD, Kitchens DM, Kothandapani RV. Prediction of spontaneous ureteral calculus passage by an artificial neural network. J Urol 2000;164:326-8.

6. Bierkens AF, Hendrikx AJ, De La Rosette JJ, Stultiens GN, Beerlage HP, Arends AJ, et al. Treatment of mid and lower ureteric calculi: Extracorporeal shock-wave lithotripsy vs laser ureteroscopy. A comparison of costs, morbidity and effectiveness. Br J Urol 1998;81:31-5

7. Francesca F, Grasso M, Da Pozzo L, Bertini R, Nava L, Rigatti P. Ureteral lithiasis: In situ piezoelectric versus in situ spark gap lithotripsy. A randomized study. Arch Esp Urol 1995;48:760-3.

8. Farsi HM, Mosli HA, Alzimaity M, Bahnassay AA, Ibrahim MA. In situ extracorporeal shock wave lithotripsy for primary ureteric calculi. Urology 1994;43:776-81.

9. Frabboni R, Santi V, Ronchi M, Gaiani S, Costanza N, Ferrari G, et al. In situ echoguided extracorporeal shock wave lithotripsy of ureteric stones with the Dornier MPL 9000: A multicentric study group. Br J Urol 1994;73:487-93.

10. Landau EH, Pode D, Lencovsky Z, Katz G, Meretyk S, Shapiro A. Extracorporeal shock wave lithotripsy (ESWL) monotherapy for stones in lower ureter. Urology 1992;40:132-6.

11. Rassweiler J, Lutz K, Gumpinger R, Eisenberger F. Efficacy of in situ extracorporeal shock wave lithotripsy for upper ureteral calculi. Eur Urol 1986;12:377.

12. Razvi HA, Denstedt JD, Chun SS, Sales GL. Intracorporeal lithotripsy with the holmium: YAG laser. J Urol 1996;156:912.

13. Teichman JM, Rao RD, Rogenes VJ, Harris JM. Ureteroscopic management of ureteral calculi: Electrohydraulic versus holmium: YAG lithotripsy. J Urol 1997;158:1357.

14. Devarajan R, Ashraf M, Beck RO, Lemberger RJ, Taylor MC. Holmium: YAG lasertripsy for ureteric calculi: An experience of 300 procedures. Br J Urol 1998;82:342.

15. Padhye AS, Yadav PB, Mahajan PM, Bhave AA, Kshirsagar YB, 
Sovani YB, et al. Shock wave lithotripsy as a primary modality for treating upper ureteric stones: A 10-year experience. Indian J Urol 2008;4:486-48.

16. Segura JW, Preminger GM, Assimos DG, Dretler SP, Kahn RI, Lingeman JE, et al. Ureteral stones clinical guidelines panel summary report on the management of ureteral calculi. J Urol 1997; 158:1915-21.

17. Liong ML, Clayman RV, Gittes RF, Lingeman JE, Huffman JL, Lyon ES. Treatment options for proximal ureteral urolithiasis: Review and recommendations. J Urol 1989;141:504.

18. Ziaee SA, Halimiasl P, Aminsharifi A, Shafi H, Beigi FM, Basiri A. Management of 10-15-mm proximal ureteral stones: Ureteroscopy or extracorporeal shockwave lithotripsy? Urology 2008;71:28-31.

19. Olsburgh J, Ramsay J. Lithotripsy for ureteric stones: Throw away the ureteroscope. BJU Int 2003;91:771-2

20. Logarakis NF, Jewett MA, Luymes J, Honey RJ. Variation in clinical outcome following shock wave lithotripsy. J Urol 2000;163:721-5.

21. Muslumanoglu AY, Tefekli AH, Altunrende F, Karadag MA, Baykal M, Akcay M. Efficacy of extracorporeal shock wave lithotripsy for ureteric stones in children. Int Urol Nephrol 2006;38:225-9.
22. Youssef RF, El-Nahas AR, El-Assmy AM, El-Tabey NA, El-Hefnawy AS, Eraky I, et al. Shock wave lithotripsy versus semirigid ureteroscopy for proximal ureteral calculi $(<20 \mathrm{~mm})$ : A comparative matched-pair study. Urology 2009;73:1184-7.

23. Landau EH, Gofrit ON, Shapiro A, Meretyk S, Katz G, Shenfeld OZ, et al. Extracorporeal shock wave lithotripsy is highly effective for ureteral calculi in children. J Urol 2001;165:2316-9.

24. Wein AJ, Kavoussi LR, Novick AC, Partin AW, Peters CA. Campbell Walsh, Textbook of Urology. $9^{\text {th }}$ ed. United Kingdom: Saunders; 2007.

25. Yencilek F, Sarica K, Erturhan S, Yagci F, Erbagci A. Treatment of ureteral calculi with semirigid ureteroscopy: Where should we stop? Urol Int 2010;84:260-4.

26. Fuganti PE, Pires S, Branco R, Porto J. Predictive factors for intraoperative complications in semirigid URS: Analysis of 1235 ballistic ureterolithotripsies. Urology 2008;72:770-4.

27. Tiselius HG. Anesthesia-free in situ extracorporeal shock wave lithotripsy of ureteral stones. J Urol. 1991;146:8-12.

28. Tiselius HG, Ackermann D, Alken P, Buck C, Conort P, Gallucci M. Working party on Lithiasis, European association of urology guidelines on urolithiasis. Eur Urol 2001;40:362-71. 